\title{
Is Teneligliptin Safe in Patients with Diabetes Mellitus Mainly with Reference to QT Prolongation
}

\author{
Shrikrishna V. Acharya ${ }^{1}$ \\ ${ }^{1}$ Department of Endocrinology, K. S. Hegde Medical Academy NITTE University, \\ Mangalore, Karnataka, India.
}

\section{ABSTRACT}

\section{BACKGROUND}

Diabetes mellitus (DM) is a chronic disease associated with polyurea, polydipsia, and polyphagia. It is associated severe complication if not controlled properly. The probability of developing cardiac arrythmia is more in patients with diabetes compared to general population. Previously, studies which used a maximum dose of $40 \mathrm{mg}$ of Teneligliptin didn't show any QT prolongation. There are hardly any studies which was done to prove the cardio safety of Teneligliptin. Therefore, we wanted to evaluate the prevalence of QT prolongation with teneligliptin in diabetic patients.

\section{METHODS}

We analysed all patients who were treated with teneligliptin. We analysed ECG of all patients before and after therapy with teneligliptin. Our main aim was to compare the QT interval in ECG before and at the end of 3 months. We also analysed their HbA1c, fasting plasma glucose (FPG), and postprandial plasma glucose (PPG) before and after therapy.

\section{RESULTS}

The mean age of these patients was $55.5 \pm 10.6$ years. They were on treatment for diabetes with a mean duration of diabetes of $7.9 \pm 5.7$ years. All patients responded well to the treatment with a reduction in HbA1c, FBS and PPBS, all of those being statistically significant. When we analysed the QT interval of all patients before and after three months of therapy, there was no significant increase in the mean QTc interval at the end of 3 months. All of them tolerated the drug without any serious adverse effects.

\section{CONCLUSIONS}

Teneligliptin in dose of $20 \mathrm{mg}$ didn't prolong QTc interval; meanwhile, it was found to be very effective in reducing the $\mathrm{HbA1c}$, fasting plasma glucose, and post prandial plasma glucose at the end of 3 months.

\section{KEY WORDS}

QT Interval, Diabetes, Teneligliptin
Corresponding Author: Shrikrishna Acharya, Department of Endocrinology, K. S. Hegde Medical Academy, NITTE University, Mangalore, Karnataka, India.

E-mail: shrikrishnaacharya@gmail.com

DOI: $10.14260 /$ jemds/2020/473

How to Cite This Article:

Acharya SV. Is teneligliptin safe in patients with diabetes mellitus mainly with reference to QT prolongation. J. Evolution Med. Dent. Sci. 2020;9(31):2171-2175, DOI: $10.14260 /$ jemds $/ 2020 / 473$

Submission 18-01-2020,

Peer Review 25-06-2020,

Acceptance 01-07-2020,

Published 03-08-2020.

Copyright (C) 2020 Shrikrishna V. Acharya. This is an open access article distributed under Creative Commons Attribution License [Attribution 4.0 International (CC BY 4.0)] 


\section{BACKGROUND}

Diabetes mellitus (DM) is a complex disease characterised by polyurea, polydipsia, and polyphagia. Chronic hyperglycaemia associated with diabetes causes many micro and macrovascular complications. Microvascular complications mainly include retinopathy, nephropathy and neuropathy. Macrovascular complications are mainly responsible for increased mortality in patients with type 2 diabetes. It is considered as one of the foremost global health problems of this era. ${ }^{[1]}$ India with second highest prevalence of diabetes is considered diabetes capital of world. As per 2017 senses, the number of people with diabetes in India are around 73 million. The sudden lifestyle change along with liberalisation and urbanisation is one of the main reasons associated with increase in the prevalence of DM in India. It is postulate that, by 2045 , the total no of patients with diabetes in India may reach to almost 134 million..[2] Type 2 diabetes accounts for about 90 percent of patients with diabetes mellitus.[3] Most patients with diabetes succumb due to Cardiovascular complications.[3] Therefore, we should be cautious during selection of medications for T2DM patients and should not serious cardiac side effects.

Common drugs used treatment of type 2 diabetes mellitus (T2DM) include metformin, sulfonylureas, meglitinides, thiazolidinediones, glucose oxidase inhibitors, and insulin. DPP4 inhibitors are newer class of drugs which are now commonly being used in the treatment of type 2 diabetes due to its safety. Other newer therapies include SGLT2 inhibitors and GLP 1 analogues. But main problem is whether these newer therapies are safe and effective in all T2DM patients' groups. ADA-EASD recommends use of newer cardio safe drugs in treatment of type 2 diabetes. After introduction of teneligliptin, number of patients on treatment with DPP-4 inhibitors has steadily increased in India. Almost 50 percent of patients on DPP 4 inhibitors are now using teneligliptin.

In 2015, DCGI approved use of teneligliptin in treatment of diabetes either as monotherapy or add on therapy after it was approved in Japan and South Korea. As per various studies and trials, teneligliptin was generally well tolerated when used treatment of diabetes as monotherapy or add-on therapy. ${ }^{[4]}$ Teneligliptin used in dose of $20 \mathrm{mg}$ once daily and it can be augmented up to $40 \mathrm{mg}$ per day if required. Researchers in Japan did extensive study on QT/QTc ratio in patients on teneligliptin and didn't find any adverse events (AEs) related to QT prolongation when used in dose of $20 \mathrm{mg}$ /day or with 40 $\mathrm{mg} /$ day of teneligliptin.[5] But, when teneligliptin was used at dose of $160 \mathrm{mg} /$ day dose, it caused significant changes in QT interval.[6]

As per US Food and Drug Administration guidelines it is compulsory to do comprehensive assessment of cardio vascular risk assessment when any glucose lowering drug is approved.[5] Various studies have demonstrated that dipeptidyl peptidase-4 (DPP4) inhibitors have many pleotropic effects on cardiovascular system due to its actions on glucagon-like peptide-1 receptors in human cardiac myocytes.[6] It causes improvements in left ventricular diastolic function, rise in adiponectin levels and many other beneficial effects of cardiac functions.[7] If we study the literature there are hardly any studies which studied QTc prolongation with Teneligliptin in Indian diabetic patients. On this background we analysed the outcome of teneligliptin on QT interval in type 2 diabetes patients.

Primary objective is to find out whether Teneligliptin in dose of $20 \mathrm{mg}$ causes any QT prolongation. Secondary objective is to find out safety and tolerability of teneligliptin. We also evaluated the efficacy of teneligliptin on control of hyperglycaemia by analysing HbA1c, fasting blood glucose and postprandial blood glucose before and after treatment with teneligliptin.

\section{METHODS}

All type 2 diabetes patients who were in the age group of 25 to 65 years with uncontrolled hyperglycaemia whose HbA1c value more than 7 are included in the study. All patients who presented to us between January 2017 to September 2019, who fulfilled the inclusion criteria are taken to the study. So, we included 80 consecutive patients irrespective of their gender for analysis who have fulfilled our inclusion criteria. We excluded all patients with type 1 diabetes, who presented to emergency department with either diabetic ketoacidosis or hypoglycaemia, patients with their baseline QTc interval $>450$ milliseconds (ms), patients who are more prone to cardiac arrythmias, for example, congestive cardiac failure, hypokalaemia, familial Long QT Syndrome, drugs which have more propensity to cause QT prolongation like CYP3A4 inhibitors, hepatic dysfunction, renal impairment, pregnant women or post-partum women feeding child and expectant mothers, known patient with history of epilepsy, history of cerebrovascular accident, and previous any cardiac illness. We included all those patients who completed three months of teneligliptin therapy at a dose of $20 \mathrm{mg}$ per day and analysed the data.

We recorded their fasting blood sugar, post prandial blood sugar and $\mathrm{HbA} 1 \mathrm{c}$ before and after treatment with teneligliptin. We collected their 12 lead ECG with rhythm strip of lead 2 before and after treatment. Physiologically QT interval in ECG is marker of repolarisation of cardiac conduction. Therefore, it is obvious that any drug that causes change in QT interval likely to change repolarisation potential and hence may cause cardiac arrythmia. So best way to find out repolarisation effect is to measure QT interval in ECG.

We collected the data of each visit where patients FPG, PPG, HbA1c and ECG recorded in their file was tabulated. We also recorded patient's examination findings and any other events described by the patients.

\section{Statistical Analysis}

Confidentiality of the data was maintained throughout the study period. All the data were tabulated and compiled in Microsoft Excel version 2013. Demographic and laboratory data were expressed in percentage and mean \pm SD; We used paired t-test to know whether data is statistically significant $(\mathrm{p}$ value) or not and if $P$ value is less than 0.05 , then it was considered to be statistically significant. 


\section{RESULTS}

We had a total of 80 patients and their data was analysed. Our cohorts mean age was $55.5 \pm 10.6$ years. They had diabetes for mean duration of $7.95 .7 \pm$ years. Out of these 80 patients, 42 were men $(52.5 \%)$ and 38 were women $(47.5 \%)$. In terms of physical condition, 43 patients had normal BMI, 30 were overweight and 7 patients were obese. About $60 \%$ of patients had hypertension meanwhile dyslipidaemia in $32.7 \%$ and stroke in $10.2 \%$ [table 2]. The most common fixed drug combination was Metformin and glimepiride. The average daily dose of metformin prescribed was $1140.2 \pm 640 \mathrm{mg}$ and that of glimepiride was $2.3 \pm 1.3 \mathrm{mg}$. Metformin and glimepiride were the most favoured fixed-dose combination used in patients with type 2 diabetes. In our cohort $57.5 \%$ of patients were on these combinations. Other combinations used were metformin and pioglitazone, metformin and gliclazide, metformin, glimepiride and pioglitazone, metformin and glimepiride and voglibose. At the start of the study mean baseline FPG level was $151.9 \pm 37.8 \mathrm{mg} / \mathrm{dL}$ and at the end of three month became $100.3 \pm 9.8 \mathrm{mg} / \mathrm{dL}$. The reduction in fasting blood glucose before and after 3 months was statistically significant ( $\mathrm{p} \leq 0.0001)$. When we analysed PPG level, it was $262.2 \pm 61.1 \mathrm{mg} / \mathrm{dL}$ at baseline and decreased to $151.9 \pm 15.3 \mathrm{mg} / \mathrm{dL}$ at the end 3rd month. Mean PPG before starting teneligliptin and at the end of 3rd month was statistically significant ( $\mathrm{p} \leq 0.0001)$. HbA1c level decreased from $8.65 \% \pm 0.9 \%$ at the start of therapy to $6.94 \% \pm 0.8 \%$ at the end of 3rd month. This decrease in HbA1c was also found to be statistically significant $(\mathrm{p}<0.0001)$. Our main objective ie mean QT interval was $405.6 \pm 25.6 \mathrm{~ms}$ at baseline and $406.1 \pm$ $25.8 \mathrm{~ms}$ at the end of $3 \mathrm{rd}$ month. We didn't find any statistically significant difference in the mean QT interval at baseline and at the end of $3^{\text {rd }}$ month ( $\left.p=0.69\right)$ (table 3 ). We didn't find any drug to drug interactions, when teneligliptin was co administered with metformin and glimepiride, pioglitazone, voglibose, glipizide and gliclazide. ${ }^{8}$

\begin{tabular}{|cc|}
\hline Gender & Number (\%) \\
Male & $42[52.5]$ \\
Female & $38[47.5]$ \\
Total BMI $\left(\mathrm{Kg} / \mathrm{m}^{2}\right)$ & 80 \\
Normal $(18.5-24.9)$ & $43[53.75]$ \\
Overweight $(25-30$ & $30[37.5]$ \\
Obese $(>30)$ & $7[8.75]$ \\
Total & $\mathbf{8 0}$ \\
OHA & $20[25]$ \\
Metformin & $3[3.75]$ \\
Glimepiride & $1[1.25]$ \\
Gliclazide & $2[2.5]$ \\
Pioglitazone & $1[1.25]$ \\
Voglibose & $46[57.5]$ \\
Metformin and Glimepiride & $2[2.5]$ \\
Metformin and Pioglitazone & $1[1.25]$ \\
Metformin glimepiride and Pioglitazone & $1[1.25]$ \\
Metformin and Glimepiride and Voglibose & $2[2.5]$ \\
Metformin and Gliclazide & $1[1.25]$ \\
\hline Metformin and Glipizide & \\
\hline Table 1. Basic Demographic Characteristics of Patients, and Oral \\
Hypoglycaemic Agents Prescribed in Combination with Teneligliptin \\
\hline
\end{tabular}

\begin{tabular}{|ccc|}
\hline Co Morbidities & Percentages of Patients & No. of Patients \\
Hypertension & $60 \%$ & 48 \\
Dyslipidaemia & $32.5 \%$ & 26 \\
Stroke & $10 \%$ & 8 \\
CAD/ACS/IHD & $25 \%$ & 20 \\
\hline \multicolumn{2}{|c|}{ Table 2. Comorbidities among Enrolled Patients } \\
\hline CAD: Coronary Artery Disease; ACS: Acute Coronary Syndrome; \\
IHD: Ischemic Heart Disease
\end{tabular}

\begin{tabular}{|c|c|c|c|c|}
\hline Parameters & $\begin{array}{c}\text { Fasting Plasma } \\
\text { Glucose } \\
(\mathrm{mg} / \mathrm{dL})\end{array}$ & $\begin{array}{c}\text { Post Prandial } \\
\text { Plasma Glucose } \\
\text { (mg/dL) }\end{array}$ & $\begin{array}{c}\text { HbA1c } \\
\text { (\%) }\end{array}$ & $\begin{array}{l}\text { QTc } \\
\text { (ms) }\end{array}$ \\
\hline Base & $151.9 \pm 37.8$ & & 8.65 & 405 \\
\hline $\begin{array}{l}\text { Follow Up at } 3^{\text {rd }} \\
\text { Month }\end{array}$ & $100.3 \pm 9.8$ & $151.9 \pm 15.3$ & $6.94 \pm 0.8$ & $406.1 \pm 25.8$ \\
\hline $\begin{array}{l}\text { Change from } \\
\text { Baseline }\end{array}$ & $.6 \pm 28$ & $110.3 \pm 45.8$ & $1.71 \pm 0.1$ & $0.6 \pm 0.2$ \\
\hline $\mathrm{p}$ value & $<0.0001$ & $<0.0001$ & $<0001$ & $=0.69$ \\
\hline
\end{tabular}

\section{DISCUSSION}

We know that cardiac repolarisation is denoted by QT interval prolongation. We know that there are many non-cardiac drugs which changes repolarisation potentials thus causing QT prolongation and hence making the patients more prone to ventricular arrhythmia. Therefore we must have the knowledge of cardiac effects of drug to determine whether the drug has capacity to change repolarisation potentials thus prolonging QT interval.[9] The cut off level which mandates caution is QT interval prolongation of more than around 5 ms.[9] Therefore any drugs causing QT/QTc interval prolongation by less than $5 \mathrm{~ms}$, unlikely to cause tachyarrhythmia. Meanwhile any drug prolonging the mean QT/QTc interval by $>20 \mathrm{~ms}$, then there is high probability of cardiac arrhythmia. But our knowledge about prolongation of mean QT/QTc interval between $5 \mathrm{~ms}$ and $20 \mathrm{~ms}$ is sparse, but some may be proarrhythmogenic.[9]

In our study, involving 80 type 2 diabetes patients who were on treatment with teneligliptin along with other oral hypoglycaemic drugs were analysed. We analysed ECG findings in all patients at the beginning of teneligliptin therapy and at the end of three months of therapy. Mean QT interval was $405.6 \pm 25.6 \mathrm{~ms}$ at the beginning of therapy and it became $406.1 \pm 25.8 \mathrm{~ms}$ at the end of study. The difference in mean QT interval was $1 \pm 0.2 \mathrm{~ms}$ at the end of 3rd month. When we analysed this difference, it was not statistically significant $(\mathrm{p}=$ 0.69). Thus, we concluded that teneligliptin in dose of $20 \mathrm{mg}$ didn't cause any QT prolongation and can be give safely in type 2 diabetes patients.

Kishimoto[9] did a study using teneligliptin in doses of 40 and $160 \mathrm{mg}$ and compared to moxifloxacin. He showed that teneligliptin in dose of $40 \mathrm{mg} /$ day prolonged the QTc by $4.9 \mathrm{~ms}$ after 3 hours after the dose meanwhile $160 \mathrm{mg} /$ day of teneligliptin significantly increased the QT by $11.2 \mathrm{~ms}$ after 1.5 hours after the dos. This $160 \mathrm{mg}$ dose results are similar to what he got with moxifloxacin i.e., $12.1 \mathrm{~ms}$ of QTc prolongation. Even though teneligliptin $160 \mathrm{mg}$ caused significant prolongation of QT interval, $40 \mathrm{mg}$ dose of teneligliptin caused QT prolongation of $4.9 \mathrm{~ms}$ which is less than the cut off of $5 \mathrm{~ms}$. Nonetheless this QT prolongation is of special importance especially when teneligliptin is given with other drugs which are likely to prolong QTc. There are many drugs in this group for example Azithromycin, Astemizole, terfenadine, Thiazide diuretics, selective serotonin uptake inhibitors, haloperidol, and obviously all antiarrhythmic drugs.[10] We also know that hypoglycaemia is one of the main aetiologies of QTc prolongation.[11] Sitagliptin also shown similar results though when used in supraphysiological doses. According to one study when sitagliptin was used in normal dose of $100 \mathrm{mg}$, it didn't cause increase in QTc interval. But when same sitagliptin used in supratherapeutic dose of 800 - 
mg it caused minimal, clinically insignificant prolongation of the QTc interval. But the dose used was very high negating the side effect potential of sitagliptin.

The PK/QTc model demonstrated an insignificant relationship between the plasma concentration of sitagliptin and the placebo subtracted QTc change from baseline. When the plasma concentration sitagliptin increased by $1000 \mathrm{nM}$ it increased the QTc by 0.59-millisecond.[15] A retrospective study by Senguptha et al showed that though teneligliptin is not associated any adverse effect in terms of QT interval, teneligliptin. Meanwhile it significantly improved diabetes control in their group of patients. The average reduction in fasting blood glucose, post prandial blood glucose and $\mathrm{HbA1c}$ reduction were statistically significant when compared to pretreatment levels. Kadowaki T et al did two 52-week, openlabel, multicentre, interventional studies to find long term efficacy of teneligliptin, the results of these studies demonstrated significant reduction in HbA1c. Teneligliptin alone reduced $\mathrm{HbA1c}$ to the extent of $-0.63 \pm 0.65 \%$, metformin with teneligliptin by $-0.78 \pm 0.75 \%,-0.76 \pm 0.70 \%$ in the group with repaglinide, $-0.89 \pm 0.64 \%$ in the voglibose combination therapy group, and $-0.81 \pm 0.76 \%$ in the sulphonyl urea therapy group. Kutoh et al, did a study with teneligliptin $20 \mathrm{mg}$ dose in newly detected diabetes mellitus as first line of therapy. In this study, $\mathrm{HbA1c}$ reduced from $10.34 \pm$ 2.06 to $8.38 \pm 2.23 \%$, and fasting blood sugar form $211.3 \pm 68.4$ to $167.3 \pm 70.2 \mathrm{mg} / \mathrm{dL}$. The study proved that teneligliptin may be used alone in treatment of type 2 diabetes mellitus. In India there are many studies done to prove the efficacy of teneligliptin. One such study by name the Treat India study,[12] showed that teneligliptin significantly reduced fasting blood sugar, post prandial blood sugar and HbA1c. Study demonstrated that FBS reduced by reduced by $51.29 \pm 35.41$ $\mathrm{mg} / \mathrm{dL}$, PPBS reduced by $80.89 \pm 54.27 \mathrm{mg} / \mathrm{dL}$ and $\mathrm{HbA} 1 \mathrm{c}$ by $1.37 \% \pm 1.15 \%$ after three months of therapy. Study by Chatterjee et al[13] also showed that 12-week teneligliptin therapy caused significant change in HbA1c, and PPG. Study by $S$ Erande $\mathrm{S}$ et al showed that teneligliptin in dose of $20 \mathrm{mg}$ is safe with respect to cardiac complications.[1]

In their prospective study they used teneligliptin in doses of 20 and $40 \mathrm{mg}$. They proved that when we use 20 or $40 \mathrm{mg}$ doses, there is no QT/QTc prolongation in diabetes mellitus patients. They also showed that teneligliptin is well tolerated by the patients with significant reduction in Fasting blood sugar, postprandial blood sugar glucose and HbA1c. Recently study by Sengupta et al shown that in their cohort of 49 patients who were treated with Teneligliptin either monotherapy or combination therapy in dose of $20 \mathrm{mg}$ tolerated the therapy well. No patients in their group exhibited prolongation of QT interval. Teneligliptin when used alone or add on therapy significantly reduced fasting blood sugar, postprandial blood sugar and HbA1c. This study also confirms that $20 \mathrm{mg}$ of teneligliptin can be safely used in type 2 diabetic patients.[14]

Several factors known delay the clearance teneligliptin from the circulation, thus increasing chances of adverse effects mainly kidney failure, liver failure and concomitant use with a CYP3A4/P-gp inhibitor. In patients with renal failure C-max of teneligliptin increased by approximately 1.04-1.12-fold, in patient with liver failure to the extent of $1.25-1.38$-fold, and when CYP3A4/P-gp inhibitor administered con currently it increases to the extent of 1.37 -fold. When teneligliptin was used in dose of 160 the C-max was estimated to be within 4.35.2 -times. In properly conducted QT prolongation study with multiple risk factors and teneligliptin in dose of 20 and $40 \mathrm{mg}$ the c-max reached was 2.1-2.6 -times.[15],[16],[17]

When Teneligliptin was prescribed with other antidiabetic drugs such as glimepiride, metformin, gliclazide glipizide, voglibose, repaglinide and pioglitazone, we didn't find any increase in adverse effects. We didn't find any adverse effect related to teneligliptin in our patients involved in the trial. But up to $30 \%$ of patients with diabetes may have cardiac co morbidities like coronary artery disease, congestive cardiac failure etc. When these patients treated with drugs like azithromycin, ketoconazole which prolong QT interval may be hazardous. There are several limitations of our study. Our sample size was small, and study was retrospective in nature. So, we require a systematically done double blind randomised study to prove safety of teneligliptin with regard to its arrhythmogenic potential. Nonetheless diabetic patients are prone to develop cardiac complications such as coronary artery disease, ischaemic heart disease and arrhythmia. When we give teneligliptin to these patients for many years, they may cause complications. So, a real-world study will help in understanding the drug-drug interaction and factors which increase the QT/QTc interval, if any. Therefore, we need to do post-marketing surveillance study to find out the adverse outcomes of teneligliptin.

\section{CONCLUSIONS}

Teneligliptin 20 mg once daily, didn't prolong the QT interval and did not show any arrhythmogenic potential. Teneligliptin was relatively well tolerated by all patients without any serious complications. Addition of teneligliptin enables reduction of FBS, PPBS and HbA1c to near normal levels in most of patients. But we need to be careful when we prescribe drugs that are likely to cause QT prolongation.

Financial or Other Competing Interests: None.

\section{REFERENCES}

[1] Erande S, Sarwardekar S, Desai B. QT/QTc safety and efficacy evaluation of teneligliptin in Indian type 2 diabetes mellitus patients: the thorough QT/QTc study (Q-SET Study). Diabetes Metab Syndr Obes 2019;12:9617.

[2] Patel DK, Sharma R, Patel H, et al. Teneligliptin: a review on cardio-renal safety. Int J Basic Clin Pharmacol 2016;5(2):229-34.

[3] Larsen PR. Williams textbook of endocrinology. $12^{\text {th }}$ edn. Philadelphia, PA: Elsevier/Saunders 2012:1371-435.

[4] Kankanala SR, Syed R, Gong Q, et al. Cardiovascular safety of dipeptidyl peptidase- 4 inhibitors: recent evidence on heart failure. Am J Transl Res 2016;8(15):2450-8. 
[5] Guidance for industry diabetes mellitus-evaluating cardiovascular risk in new antidiabetic therapies to treat type 2 diabetes. Federal Register 2008;73(245):77724-5.

[6] Bullock BP, Heller RS, Habener JF. Tissue distribution of messenger ribonucleic acid encoding the rat glucagonlike peptide-1 receptor. Endocrinology 1996;137(7):2968-78.

[7] Hashikata T, Yamaoka-Tojo M, Kakizaki R, et al. Teneligliptin improves left ventricular diastolic function and endothelial function in patients with diabetes. Heart Vessels 2016;31(8):1303-10.

[8] Fisman EZ, Tenenbaum A. Antidiabetic treatment with gliptins: focus on cardiovascular effects and outcomes. Cardiovasc Diabetol 2015;14:129.

[9] Guidance for Industry: E14 clinical evaluation of QT/QTc interval prolongation and proarrhythmic potential for non-antiarrhythmic drugs. http://www.file:///C:/Users/admin/Downloads/USFDA $\% 20$ Guidance\%20documentE14\%20Clinical\%20Evaluation\%20of\%20QTc. pdf.

[10] Kishimoto M. Teneligliptin: a DPP-4 inhibitor for the treatment of type 2 diabetes. Diabetes Metab Syndr Obes 2013;6:187-95.

[11] Singh AK. Efficacy and safety of teneligliptin. Indian J Endocrinol Metab 2017;21(1):11-7.
[12] Ghosh S, Trivedi S, Sanyal D, et al. Teneligliptin real-world efficacy assessment of type 2 diabetes mellitus patients in India (TREAT-INDIA study). Diabetes Metab Syndr Obes 2016;9:347-53.

[13] Chatterjee AK. Teneligliptin add on to monotherapy treatment in patients with type 2 diabetes. Int J Res Med Sci 2018;6(4):1356-61.

[14] Sengupta S, Rathod A, Suryawanshi S, et al. Effect of teneligliptin on QT interval in type 2 diabetes mellitus patients: a retrospective evaluation. Int J Sci Stud 2019;6(10):88-91.

[15] Report on the Deliberation Results. Evaluation and licensing division, pharmaceutical and food safety bureau. Ministry of Health, Labour and Welfare 2012.

[16] Halabi A, Maatouk H, Siegler KE, et al. Pharmacokinetics and safety of teneligliptin in subjects with hepatic impairment. Clin Pharmacol Drug Dev 2014;3(4):290-6.

[17] Kadowaki T, Marubayashi F, Yokota S, et al. Safety and efficacy of teneligliptin in Japanese patients with type 2 diabetes mellitus: a pooled analysis of two phase III clinical studies. Expert Opin Pharmacother 2015;16(7):971-81. 